\title{
Crecimiento del medio construido, turismo y problemáticas ambientales en la localidad de Santa Rosa de Calamuchita (Córdoba) entre los años 1990-2017
}

\author{
NATALIA RIBERT* , FRANCO GASTÓN LUCERO*, GABRIELA INÉS \\ MALDONADO**
}

*Departamento de Geografía, Facultad de Ciencias Humanas, Universidad Nacional de Río Cuarto, Argentina.

** Departamento de Geografía, Facultad de Ciencias Humanas, Universidad Nacional de Río Cuarto; Instituto de Estudios Sociales, Territoriales y Educativos, CONICET-UNRC, Argentina.

natalia8ribert@gmail.com; flucero@hum.unrc.edu.ar; gabyinesm@gmail.com

\section{RESUMEN}

En el presente trabajo se expone parte de los resultados obtenidos de un proyecto de investigación vinculado a una Beca de Ayudantía de Investigación otorgada por la Secretaría de Ciencia y Técnica de la Universidad Nacional de Río Cuartor. Este trabajo tuvo como objetivo general estudiar y analizar las características de la ampliación del medio construido vinculado al turismo en la localidad de Santa Rosa de Calamuchita (Córdoba), y reconocer su articulación con la emergencia de problemáticas ambientales en el área, entre los años 1990 y 2017. Para ello, se trabajó con una metodología de tipo inductiva y esencialmente cualitativa y con algunas técnicas de carácter cuantitativo.

En cuanto a los principales resultados alcanzados, se ha podido dar cuenta de una notable expansión del medio construido y de un significativo crecimiento poblacional producto de la actividad turística. Del análisis de las imágenes satelitales y de la cartografía obtenida, se ha observado que la expansión del medio construido ha avanzado, a través de diversas modalidades de loteo,

1 Desarrollada en el marco de un proyecto PPI del Departamento de Geografía de la Universidad Nacional de Río Cuarto, titulado: "Territorio usado en el sur de Córdoba: lazos de articulación, cooperación y conflicto" y dirigido por la Dra. Gabriela Inés Maldonado.

Recepción: 22/02/2018 | Evaluación: 26/07/2018 | Aceptación: 02/09/2018 
hacia los distintos puntos cardinales del área de estudio y sobre zonas con cobertura de suelo vegetal y con distintos grados de pendiente. Las principales problemáticas ambientales reconocidas se relacionan específicamente con: el reemplazo de la cobertura vegetal, la introducción de especies exóticas, el avance de las construcciones hacia zonas con mayor pendiente y, por último, la multiplicación y falta de tratamiento de los residuos domésticos.

PALABRAS CLAVE: medio construido; turismo; problemáticas ambientales; Santa Rosa de Calamuchita. 


\section{ABSTRACT}

THE GROWTH OF CONSTRUCTED ENVIRONMENT, TOURISM AND ENVIRONMENTAL PROBLEMS IN SANTA ROSA DE CALAMUCHITA CITY (CÓRDOBA) BETWEEN THE YEARS 1990-2017

This paper presents part of the results obtained from a research project linked to a Research Grant awarded by the Secretary of Science and Technology of University National of Río Cuarto ${ }^{2}$. This paper had as general objective to study and analyze the characteristics of the expansion of the constructed environment linked to tourism in Santa Rosa de Calamuchita City, and recognize the articulation with the emergence of environmental problems in the area, between the years 1990 and 2017. For this, was used an inductive and essentially qualitative methodology and some quantitative techniques.

Respect of the main results, it has been possible to detect a remarkable expansion of the constructed environment and a significant population growth resulting from the tourist activity. From the analysis of the satellite images and the cartography obtained, it has been observed that the expansion of the constructed environment has advanced, through various modes of lot, towards the different cardinal points of the study area and over areas with vegetation cover and with different degrees of slope. The main environmental problems recognized were: the replacement of the vegetation cover, the introduction of exotic species, the advance of the constructions towards zones with greater slope and, finally, the multiplication and lack of treatment of domestic waste.

KEYWORDS: constructed environment; tourism; environmental problems; Santa Rosa de Calamuchita.

2 Developed through of a PPI project of the Departament of Geography of the University National of Río Cuarto, entitled: "Territory used in the south of Cordoba: links of articulation, cooperation and conflict" and directed by Dr. Gabriela Inés Maldonado. 


\section{RESUMO}

\section{CRESCIMENTO DO MEIO CONSTRUÍDO, TURISMO E PROBLEMAS \\ AMBIENTAIS NA CIDADE DE SANTA ROSA DE CALAMUCHITA (CÓRDOBA) ENTRE OS ANOS 1990-2017}

O presente trabalho expóe parte dos resultados alcançados de um projeto de pesquisa vinculado a uma Bolsa de Pesquisa concedida pela Secretária de Ciência e Técnica da Universidade Nacional do Río Cuarto 3 . Este trabalho teve como objetivo geral estudar e analisar as características da ampliação do meio construído vinculado ao turismo na cidade de Santa Rosa de Calamuchita (Córdoba) e reconhecer sua articulação com a emergência de problemáticas ambientais na área, entre os anos 1990 e 20I7. Para isso, trabalhou-se com uma metodologia de tipo indutiva e essencialmente qualitativa e com algumas técnicas de caráter quantitativo.

Quanto aos principais resultados alcançados, pôde-se dar conta de uma notável expansáo do meio construído e de um significativo crescimento populacional produto da atividade turística. Da análise das imagens de satélite e da cartografia obtida, verificou-se que a expansão do meio construído avançou, através de diversas modalidades de loteio, para os diferentes pontos cardeais da área de estudo e sobre zonas com cobertura de solo vegetal e com diferentes graus de inclinação. As principais problemáticas ambientais reconhecidas relacionam-se especificamente com: a substituição da cobertura vegetal, a introduçáo de espécies exóticas, o avanço das construçóes para zonas com maior inclinação e, por último, a multiplicação e a falta de tratamento dos resíduos domésticos.

PALAVRAS-CHAVE: meio construido; turismo; problemas ambientais; Santa Rosa de Calamuchita.

3 Desenvolvida no âmbito de um projeto PPI do Departamento de Geografia da Universidade Nacional do Río Cuarto, intitulado: "Território usado no sul de Córdoba: laços de articulação, cooperação e conflito" e dirigido pela Dra. Gabriela Inés Maldonado. 


\section{Introducción}

El turismo es una de las actividades económicas que más desarrollo ha tenido durante los últimos años en la Argentina y en el mundo. Es el medio por el cual la economía de algunos países se ha visto beneficiada con importantes inversiones para que dicha actividad se desarrolle y logre así mejorar su competitividad y sustentabilidad.

En Argentina, el Plan Federal Estratégico de Turismo Sustentable (Ministerio de Turismo de la Nación, 20II) identifica seis regiones para el territorio turístico nacional. Una de ellas coincide con los límites político-administrativos de la provincia de Córdoba, cuya ubicación en el centro del país la favorece para posicionarse como un importante núcleo turístico, tanto emisor como receptor, de turistas provenientes de diferentes regiones del país y el mundo. Las cifras relativas a diferentes indicadores como: afluencia turística, oferta de alojamiento, promedio de estadías y pernoctaciones, origen de los turistas, niveles de inversión en turismo, estándares de calidad turística, entre otros, la ubican como una de las regiones turísticas más relevantes en el contexto nacional. Maffini (20I5) señala que este incremento refuerza las clásicas representaciones positivas acerca del turismo como promotor del desarrollo y sus potencialidades para superar contextos de crisis, incentivar a la actividad económica o generar empleo.

El área vinculada a la localidad de Santa Rosa de Calamuchita (Córdoba), convertida en territorio turístico fundamentalmente desde mediados del siglo pasado, ha registrado profundas transformaciones vinculadas a la expansión del medio construido a causa de, entre otras, la construcción de hospedajes turísticos y de áreas de recreación. Este proceso de expansión, al igual que lo que acontece en los diversos lugares turísticos de las sierras de Córdoba, se da a expensas de una intensa transformación del entorno que involucra: modificación de las cuencas hídricas, cambios en la vegetación autóctona, disminución de las áreas naturales, cambios en la cobertura de suelo, incremento de impermeabilización del suelo, etc. Todo ello supone un encuentro solidario, conflictivo y contradictorio entre el turismo, la expansión del medio construido y la transformación del ambiente.

Para realizar esta investigación, fue necesario partir de la premisa de considerar a la actividad turística en un contexto teórico que piense la construcción social del territorio como turístico. Siguiendo a Berton- 
cello (2002), el análisis del turismo en sus vinculaciones con el territorio, obliga a comprender el contexto social más amplio en el que éste se inserta. Así, las transformaciones sociales atraviesan y se ven atravesadas por el turismo, en un proceso en el que se valorizan y se diferencian lugares que van configurando un "territorio turístico". Por su parte, Maffini (20I5) señala que la conceptualización de los atractivos turísticos como resultados de procesos sociales y geográficos se opone a la que comúnmente se les da en los abordajes más clásicos, que los conciben como rasgos territoriales intrínsecos. En definitiva, y siguiendo a Santos y Silveira (2005), podríamos decir que es la forma en que el territorio es usado la que determina su construcción como territorio turístico.

El presente trabajo se desarrolló en el marco de un Proyecto de Investigación (PPI) titulado "Territorio usado en el sur de Córdoba: lazos de articulación, cooperación y conflicto”, aprobado por la Secretaría de Ciencia y Técnica de la Universidad Nacional de Río Cuarto y dirigido por la Dra. Gabriela Inés Maldonado, y tuvo por objetivo estudiar y analizar las características de la ampliación del medio construido vinculado al turismo en la localidad de Santa Rosa de Calamuchita (Córdoba), y reconocer su articulación con la emergencia de problemáticas ambientales en el área, entre los años 1990 y 2017.

Para ello, se trabajó con una metodología de tipo inductiva y esencialmente cualitativa y con algunas técnicas de carácter cuantitativo. Específicamente, se analizaron antecedentes de investigaciones similares en el área de estudio; se efectuaron entrevistas semiestructuradas a informantes claves y se analizaron los datos de los Censos Nacionales de Población, Hogares y Vivienda (CNPHyV) del Instituto Nacional de Estadísticas y Censos (INDEC). Asimismo, se trabajó con el procesamiento de imágenes satelitales y se construyó la cartografía temática correspondiente en ambiente de Sistema de Información Geográfica (SIG).

En cuanto a los antecedentes de investigación vinculados al turismo en el área de estudio, estos son escasos. Se pueden señalar los trabajos de: Maffini (20I4, 20I5), quien estudia los procesos de valorización turística en las sierras del mediodía de Córdoba; los trabajos de Sosa et al (2013 y 2015), Cabral y Bais (2014a y b), García et al (2015) y García y Perrone (20I7) quienes estudian la actividad turística en las localidades de Alpa Corral, El Chacay y Las Albahacas. A su vez, Brandi et al (2015) estudian el impacto de la introducción de especies exóticas en los alrededores de la localidad de Alpa Corral, en parte producto de los impactos generados 
por la acelerada urbanización devenida del turismo. A nivel provincial, se pueden citar también los trabajos de Bertoncello (2006) y Pastoriza (20II), quienes analizan las condiciones generales en las cuales la práctica turística se lleva a cabo, teniendo en cuenta sus múltiples vinculaciones con el territorio, y dando cuenta además del amplio proceso histórico que reconoce la tradición turística de la provincia de Córdoba.

\section{Ubicación y caracterización del área de estudio: Santa Rosa de Calamuchita, Córdoba}

Santa Rosa de Calamuchita es una localidad ubicada de la provincia de Córdoba, entre las Sierras Grandes y las Sierras Chicas a orillas del río Santa Rosa (figura I). Más específicamente, se encuentra situada en el departamento de Calamuchita a $96 \mathrm{~km}$ de la capital provincial y a 30 $\mathrm{km}$ de la localidad de Villa Yacanto, con las cuales se conecta a través de las rutas provinciales $\mathrm{N}^{\circ} 5$ y $\mathrm{N}^{\circ} 228$, respectivamente. En la actualidad, se caracteriza por ser una importante ciudad turística en la región, con I2.395 habitantes (según los datos del CNPHyV del INDEC, año 20IO) y un interesante crecimiento poblacional de alrededor del 58,15\%. Dicho crecimiento se debió, en gran parte, a la anexión de algunos pequeños centros urbanos (específicamente las comunas de Santa Rosa del Río, Santa Mónica, Posta Carreta, La Olla y El Portezuelo) lo que le permitió, en el año 2006, ascender a la categoría "ciudad". 


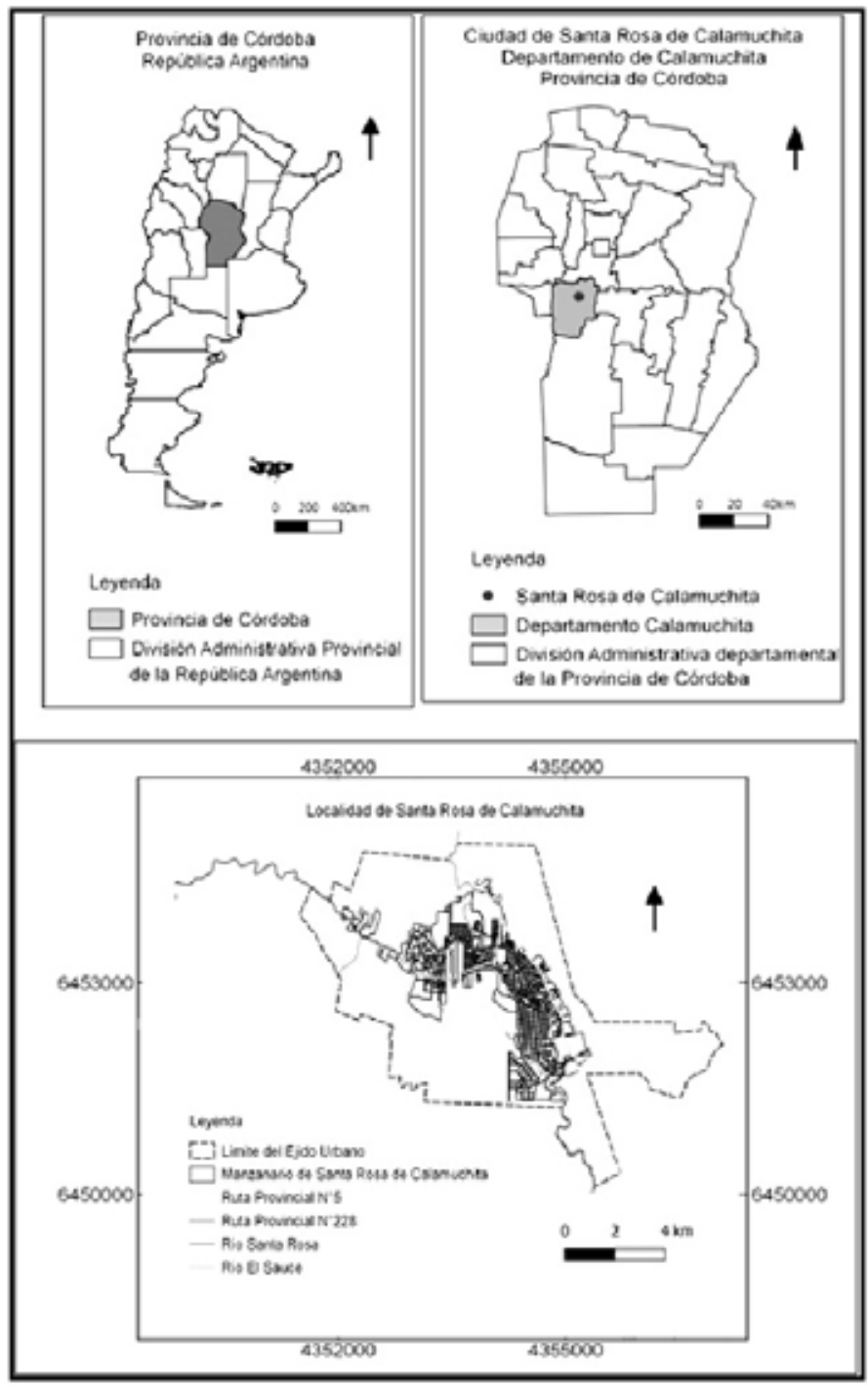

Fuente: Ribert, sobre la base de imágenes satelitales Landsat ETM8 (2018).

Figura 1. Localización del área de estudio 


\section{El desarrollo de la actividad turística en la Argentina}

Argentina vive un notable auge turístico en la actualidad, observable tanto en el incremento de los movimientos de turistas locales, nacionales e internacionales como así también en la multiplicación de lugares de destino y de productos turísticos. Esta situación ha llevado a un creciente interés académico por el estudio del turismo, revirtiendo de tal manera la situación contraria que había predominado en el país hasta hace poco tiempo (Bertoncello, 2006).

La Argentina presenta un amplio conjunto de destinos turísticos, ya sea por su consolidación histórica, su presencia en las representaciones turísticas o por el volumen de turistas que recibe. Si tomamos en cuenta las distintas regiones de nuestro país, se pueden destacar diferentes lugares turísticos: en la Región del Noroeste se destacan la Quebrada de Humahuaca y las ciudades de Salta y Tucumán; en el nordeste, las Cataratas del Iguazú; en cuyo, la ciudad de Mendoza y los faldeos montañosos próximos a ella; en la Región Centro, dominan las Sierras de Córdoba; y en la Región Pampeana, Mar del Plata, los diferentes balnearios de la costa atlántica bonaerense y también la ciudad de Buenos Aires; por último, en la Región Patagónica se encuentran los parques nacionales del área andina, destacándose el Parque Nacional Nahuel Huapi y la ciudad de Bariloche (Bertoncello 2006).

El turismo en la Argentina comienza a desarrollarse en las últimas décadas del siglo XIX, en correlación con el proceso de organización nacional y la consolidación del modelo económico agroexportador. Se trata de un turismo que puede adscribirse al denominado turismo de elite, en tanto es practicado sólo por los sectores sociales más acomodados de la población, quienes emulando comportamientos sociales de grupos europeos con los que se identificaban, comienzan a viajar con fines turísticos hacia algunos lugares del país que cumplían con una serie de requisitos tales como: lugares de playa, de montańa, con paisajes pintorescos, similares a los que muestran los destinos turísticos europeos (Villar y Bilbao, 200o).

Bertoncello (2006) señala que con el transcurso del tiempo, a mediados del siglo XX, se comienza a masificar esta práctica en consonancia con los cambios sociales generales del país, los cuales conducirían a la consolidación de prácticas turísticas que pueden ser adscriptas al denominado turismo masivo, no sólo por el aumento del volumen de turistas 
sino también por la vinculación del turismo con el mundo del trabajo y su reconocimiento como un derecho asociado al mismo. En efecto, en Argentina, el mundo del trabajo presentó una paulatina consolidación de derechos laborales tales como la limitación del tiempo de trabajo diario y semanal, los días de descanso y, finalmente, el descanso anual pago: las vacaciones (Cabrera, 2003). Asimismo, vale considerar también la importancia que tuvo la difusión del transporte automotor, que desplazó al ferrocarril de su primacía absoluta, para el transporte de pasajeros. El automóvil permitió una mayor flexibilidad a los desplazamientos, permitiendo tanto el viaje hacia lugares no servidos por el ferrocarril como así también el desplazamiento más aleatorio y por etapas, con la paulatina consolidación de la red de caminos (Bertoncello, 2006).

\section{El turismo en las Sierras de Córdoba y en el Valle de Calamuchita}

Además del desarrollo turístico de la Argentina en torno al mar, Pastoriza (20II) señala que también comenzaron a tener visibilidad aquellos lugares que, además de sus características paisajísticas, se identificaban por su clima, especialmente benéfico para la cura de ciertas enfermedades, emergiendo así la idea de un turismo saludable. De esta manera, surgieron dos principales horizontes vacacionales para el descanso y la salud: Mendoza y Córdoba.

A fines del siglo XIX y principios del XX, con el surgimiento de algunos hoteles de salud en Alta Gracia, Cosquín, La Falda, Deán Funes y Jesús María, Córdoba se consagró como un importante espacio social y cultural. Asimismo, producto de los atractivos paisajísticos y culturales se valorizaron otros lugares para el turismo (como San Jorge, Ascochinga, Yacanto y Los Cocos).

En particular, Santa Rosa de Calamuchita se puede considerar como una ciudad turística desde principios de 1900, pero en comparación con otros pueblos turísticos, no tenía gran desarrollo en cuanto a su infraestructura para albergar un número grande de turistas, ya que según Galera Morant, un historiador de la ciudad, "solo existía lo que hoy se conoce como 'La Estancia', es decir, lo que fue el primer hotel de Santa Rosa de Calamuchita, por 1930 aproximadamente" (entrevista personal, septiembre de 20I7). 
Sin embargo, con la instalación de otros hoteles, tales como el Calamuchita Hotel, Hotel Torino y Hotel Viena, se fue fomentando su perfil turístico. Durante esa época, y como sucedía en otros centros turísticos del país, la clase social que veraneaba en el lugar era principalmente la elite, aunque posteriormente "...este escenario fue cambiando con el auge de algunas políticas sociales, hacia el desarrollo de un turismo popular (década del '50). Esta situación llevó a que el gobierno de la provincia de Córdoba y Buenos Aires, establezcan un convenio para cumplir con la consigna -Usted paga el viaje, nosotros el hospedaje-, para lo cual se construyó el Hotel Evita. Dicha consigna facilitó la llegada de grandes masas de población bonaerense a las Sierras de Córdoba, logrando así un intenso desarrollo en el turismo, generando mayores inversiones en infraestructuras para poder albergar en la ciudad a todos los turistas que llegaban a Santa Rosa de Calamuchita" (Pastoriza, 20II:52).

Luego, a principios del siglo XXI, producto de la sanción de la Ley de Alojamiento de Córdoba $\mathrm{N}^{\circ} 6483$, comienza el auge de las inversiones en el rubro del alojamiento, desde casas hasta hoteles. Incluso, debido a la situación económica en la que se encontraba el país, era más seguro invertir el dinero en el ámbito inmobiliario, por lo que muchas personas que contaban con la disponibilidad económica para hacerlo, aprovecharon la situación realizando una o más inversiones en inmuebles.

\section{El proceso histórico de organización de Santa Rosa de Calamuchita}

Tal como menciona Signorile (2018), en el sitio web de Santa Rosa de Calamuchita ${ }^{4}$, los Comechingones y Sanavirones fueron los primeros pobladores indígenas del lugar, quienes se encontraban organizados en pueblos y ocupaban distintas partes de la actual provincia de Córdoba. Una de ellas es la que le dio el nombre a Santa Rosa, la llamada Ctalamochita. Esta denominación "Calamuchita" tuvo su origen en la lengua indígena que evoca: ctala (tala) muchi (molle), "ita" (abundancia). Esto significa que hay abundancia de dos árboles autóctonos típicos de las sierras cordobesas: la tala y el molle.

4 Sitio web: http://www.starosacalamuchita.com.ar/la-ciudad/historia/ (consultado en septiembre de 2018). 
Luego y en honor a la Santa Limeña, la familia Carranza nombra a su estancia, ubicada junto al río, "Santa Rosa”, y más tarde sus herederos la venden al padre Vicente Peñaloza, quien construye la capilla. Siguiendo a Signorile (20I8), un Io de diciembre del año I877, la familia Baños-Prado Núnez, dona una manzana para poblar los alrededores de la capilla, dando origen a un poblado que crece de manera espontánea, conocido como "Villa Santa Rosa". Por dicha razón ésta es considerada su fecha de fundación. Allí se trazaron las primeras calles: Libertad, Córdoba y Costanera, las cuales en la actualidad son las principales vías céntricas de la localidad. Además, se instalan: una escuela, una estafeta postal, algunas viviendas, un almacén de ramos generales y otros comercios. En 1923 Estanislao Ramón Baños vende a Diego Garzón el sector centro de la estancia quien la lotea, urbanizando el lugar en 1935. "Otros hitos importantes para la localidad fueron la constitución de la 'Cooperativa de Luz y Fuerza Ltda.' en el año 1936 y el primer colectivo de la Empresa Diviú que arriba en el año 1932, con un recorrido entre Córdoba, Los Reartes y Santa Rosa de Calamuchita. También lo es la construcción del vado que comunica a Villa Incor con la localidad en la década del '50" (Galera Morant, 20I0:20).

Según lo comentado por un historiador local, Santa Rosa de Calamuchita siempre estuvo ligada a la actividad turística, y el indicio para esto es la creación del primer hotel en el año 1929 (Hotel Roasenda) el cual se encontraba ubicado en un dominio de 700 ha bajo la dirección de Don Pedro Roasenda. Allí también funcionaba el correo y el telégrafo. En la actualidad este es el predio de "La Estancia".

Santa Rosa de Calamuchita era una localidad pequeña, pero a medida que transcurrieron los años se fue consolidando como un territorio turístico, expandiendo así su medio construido. A partir del año 2006, Santa Rosa de Calamuchita comenzó un proceso de absorción de otros pequeños centros urbanos para adquirir la categoría de "ciudad", dado que demográficamente no podía ser considerada como tal por sí sola. Se puede citar a: Villa Incor, Posta Carreta, La Olla, Santa Rosa del Río, El Portezuelo y Santa Mónica, consideradas pequeños poblados que al expandirse lograron la unión territorial. De ellos, Santa Mónica fue el centro urbano más importante de todos los que incorpora Santa Rosa de Calamuchita, ya que para 2006 era el sector de la ciudad con mayor cantidad de habitantes. Según Galera Morant (2013:24) “...surge en 1920, aproximadamente, como Estancia Santa Mónica, Calamuchita 
Estancias S.R.L. La zona era apta para realizar todo lo que se proponía, con calles curvas, terrenos irregulares, vegetación autóctona y el respeto por el río. Esta villa serrana fue creciendo organizadamente y con el tiempo formó parte de lo que hoy es la ciudad de Santa Rosa de Calamuchita".

\section{Características socio-demográficas de Santa Rosa de Calamuchita (1990- 2010)}

Según los datos del CNPHyV del INDEC del año 199I, la población de la localidad de Santa Rosa de Calamuchita era de 7718 habitantes. Como se ha mencionado anteriormente, la localidad desde sus inicios estuvo relacionada con la actividad turística, aunque también se desarrollaban actividades agrícolas-ganaderas. Sin embargo, se considera que fue después de la creación de la Dirección de Turismo (I99I) cuando esta actividad renueva su impulso en la localidad. Inicialmente, ésta no era la más importante. Durante la década de los ' 90 , en el marco del contexto neoliberal, con la apertura económica y de los mercados, tomaron relevancia algunas actividades económicas que antes estaban poco desarrolladas, como el caso del turismo, lo que permitió a la localidad de Santa Rosa de Calamuchita convertirse en una de las principales ciudades turísticas del sur de las Sierras de Córdoba, situación que se mantiene en la actualidad. Debido a esto, hacia el ańo 200I, se incrementa su población a 9504 habitantes (CNPHyV del año 200I), sin tener en cuenta la cantidad de población de Santa Mónica, que a partir del año 2006 se integraría a Santa Rosa de Calamuchita para que la misma pudiera constituirse como ciudad (lo que a su vez le permitiría recibir mayor coparticipación por parte del Estado provincial), y así consagrarse como la ciudad turística más importante del Valle de Calamuchita.

El crecimiento de la localidad durante el año 200I se puede explicar debido a que para ese momento Argentina se encontraba inmersa en una crisis económica que llevó al gobierno nacional a implementar una medida denominada "corralito". Como resultado de esta medida,

5 "En el año 2001, el país estaba financiera y políticamente en ruinas: el riesgo-país alcanzó niveles históricos, reflejando la certeza de los mercados sobre un default, las reservas del Banco Central se habían derrumbado, y los bancos sobrevivían sólo gracias a una fuerte 
creció la desconfianza en el sistema bancario y las personas con mejor situación económica ya no depositaban su dinero en los bancos, sino que lo invertían en el sector inmobiliario. Es por ello que para el año 200I, Santa Rosa de Calamuchita empieza a crecer en número de edificaciones privadas (ya sean casas particulares, segundas residencias y/o complejos de cabañas), comportamiento que también se identificaba a nivel demográfico. Lo mencionado se puede constatar a través de los datos del régimen de tenencia de la vivienda del CNPHyV del año 200I, por medio de los cuales se concluye que el $66 \%$ de la población era propietaria de la vivienda y del terreno, un $17 \%$ alquilaba, un II \% era ocupante con préstamo, y el $6 \%$ restante involucra otras categorías.

En cuanto al tipo de vivienda, para el mismo año, el mismo censo releva que éstas son mayoritariamente del tipo $\mathrm{A}^{6}$, las cuales involucran al $82 \%$ del total de las viviendas. El tipo $\mathrm{B}^{7}$ representa tan solo al $9 \%$ del total; le sigue el "departamento" con el $6 \%$, la "casilla" con el $2 \%$, el "rancho" con el $0.5 \%$, y "otros" con el $0.5 \%$.

Por otro lado, se puede analizar el Índice de Necesidades Básicas Insatisfechas (NBI) de la población de Santa Rosa de Calamuchita, el cual no es relevante en gran porcentaje. Esto se ve reflejado en que el $84 \%$ del total de la población no presenta NBI, mientras que el II \% de la población sufre NBI de tipo I: hacinamiento (hogares que tuvieran más de tres personas por cuarto); el $2 \%$ presenta NBI de tipo 2 (vivienda: hogares en una vivienda de tipo inconveniente -pieza de inquilinato, vivienda precaria u otro tipo, lo que excluye casa, departamento y rancho) y, por último, el $3 \%$ de los hogares sufre NBI de tipo 3 (condiciones sanitarias: hogares que no tuvieran ningún tipo de retrete).

Para el 20Io, según el CNPHyV, la población de Santa Rosa de Calamuchita alcanzaba los 12830 habitantes (que en 2006 ya había sido decretada ciudad). Pero, como se mencionó anteriormente, para ello se debió anexar a distintas comunas que se encontraban a sus alrededores, motivo por el cual la ciudad cuenta actualmente con 2I barrios.

limitación gubernamental sobre el retiro de dinero -conocida popularmente como corralito-" (Gervasoni, 2003:13).

6 El tipo A se refiere a viviendas con piso de cerámica, baldosa, mosaico, mármol, madera o alfombra, tienen provisión de agua por cañerías dentro de la vivienda e inodoro con descarga de agua.

7 El tipo B son casas con piso de tierra, de ladrillo suelto o de otro tipo de material y no posee inodoro con descarga de agua, ni provisión de agua por cañerías dentro de la vivienda. 
Para los años 2007-2008 se observa un importante crecimiento del medio construido en la ciudad, impulsado fundamentalmente por las construcciones de segundas residencias ${ }^{8}$ y casas permanentes, que se refleja en el crecimiento de la mancha urbana. Hacia el año 20ı, el tipo de viviendas existentes eran: casas (91.9\%), departamentos (5.8\%), rancho (0.5\%), casilla (I.3\%) y otras (0.5\%). En cuanto al régimen de tenencia se puede decir que, el $64.4 \%$ eran propietarios de la vivienda y el terreno, el I.9 \% propietarios de la vivienda, el $22.9 \%$ inquilinos, el $7.3 \%$ ocupantes por préstamo, el I.9 \% ocupantes por trabajo y el I.6 \% se encontraban en otra situación ( $\mathrm{CNPHyV}, 2010)$. En ese mismo año, los datos del censo indicaban que sólo el 9.6 \% de la población de Santa Rosa de Calamuchita presentaba algún tipo de NBI. De aquí pueden distinguirse deficiencias en: la vivienda $(2.9 \%)$, condiciones sanitarias ( $1.7 \%)$, hacinamiento $(4.4 \%)$, asistencia escolar ( $0.3 \%)$ y capacidad de subsistencia (0.3\%).

\section{El proceso de transformación territorial vinculado al turismo}

Según García (2018), la actividad turística en el Valle de Calamuchita como en otras zonas turísticas del país, a comienzos del siglo XXI, se vio plasmada en el avance de inversiones inmobiliarias en residencias consignadas al alojamiento del turista. Este proceso puso en marcha una serie de prácticas y estrategias de múltiples agentes sociales que, directa o indirectamente, se manifestaban en el desarrollo turístico local y que se cristalizaban en el crecimiento urbano de la ciudad.

Las transformaciones territoriales que se produjeron en la localidad de Santa Rosa de Calamuchita en la década de los noventa, responden a una serie de cambios en el sector inmobiliario que se produjeron a escala global y nacional. En esta época se observó "un crecimiento del sector inmobiliario con niveles equilibrados que comenzó a disminuir hacia fines del período de la convertibilidad, dado un nuevo escenario donde la economía real iba siendo desplazada por la economía financiera. En el

8 El concepto de segundas residencias es utilizado por Donadoni et al. (2012) para hacer referencia a la construcción de viviendas que realiza un sector de la sociedad en un determinado lugar (generalmente un destino turístico), el cual es visitado con fines recreativos y de ocio. 
caso de la Argentina, el mercado inmobiliario era pequeño en comparación con otras economías del mundo, aunque siempre ha mostrado un importante crecimiento desde el área de la construcción, especialmente en las décadas de los años '50, '6o y '70, en los años '80 y '90 este incremento se estabilizó contrastando con el natural crecimiento demográfico" (Pertierra Cánepa y Pantanetti, 20Ir:9).

El crecimiento de la localidad de Santa Rosa de Calamuchita comenzó a evidenciarse con relevancia a partir del año 1990 (figura 2), momento en que la mancha urbana empieza a expandirse de a poco, respondiendo a las tendencias que se desarrollaban en esa época vinculadas al crecimiento del sector inmobiliario y las construcciones. De acuerdo a las observaciones realizadas, se evidenció que el crecimiento se produjo a lo largo de dos ejes dinamizadores: en un principio, fue a lo largo del río Santa Rosa el cual atraviesa toda la localidad de noroeste a sureste y, luego, comenzó a expandirse hacia el norte debido a la creación de la ruta provincial No 5 . En su momento, la localidad era bastante pequeña y con pocos habitantes, por lo que su extensión no abarcaba mucha superficie (sólo 366 ha en el año 1990). También vale señalar que en las inmediaciones de Santa Rosa de Calamuchita se encontraban dos pequeñas comunas; una denominada Santa Rosa del Río, al noroeste de la mencionada localidad y otra llamada Santa Mónica, hacia el oeste, que también se encontraban en franco crecimiento debido a la dinámica propia de la actividad turística.

Luego de la salida de la convertibilidad y con el comienzo de un período de devaluación sostenida de la moneda nacional y de colapso institucional, el mercado presentó indicadores de la actividad en fuerte caída. En este contexto, Pertierra Cánepa y Pantanetti (201I) expresan que la inversión inmobiliaria se fue consolidando como argumento de resguardo del poder adquisitivo y como reserva de valor para muchos inversores minoristas adversos o carentes de información técnica que les permitiera elegir otras alternativas. Este escenario fue el que generó lo que se conoce como el "boom inmobiliario". En este sentido, la localidad de Santa Rosa de Calamuchita no se encontraba excluida de estas tendencias, sino que a partir de dicho período comenzó a crecer tanto su población como también el medio construido. A partir de entonces, los índices de construcción no han cesado de incrementarse, acompañados por el aumento sostenido de los costos de la construcción y del valor de la tierra. 
Santa Rosa de Calamuchita fue creciendo a ritmo acelerado, llegando a duplicar su tamaño, hasta aproximadamente 66I ha, superficie en la que hasta ese momento no se incluían las comunas de Santa Rosa del Río (67 ha) y Santa Mónica (62 ha), que también crecieron en paralelo a Santa Rosa de Calamuchita respetando los dos ejes dinamizadores anteriormente mencionados. Igualmente, se puede observar que estas comunas y Santa Rosa de Calamuchita, comenzaron a expandirse horizontalmente hasta lograr unirse entre ellas.

Hacia los años 2004 y 2005, de acuerdo a la información brindada por un funcionario de la Cooperativa de Santa Mónica, la ciudad de Santa Rosa de Calamuchita comenzó a experimentar un crecimiento de su medio construido más acelerado. Lo mismo evidenciaron las comunas de Santa Mónica y Santa Rosa del Río. De tal manera, este período podría considerarse como un momento clave debido a que el impulso turístico dentro de todo el período analizado en la investigación (199020I7) que repercutió de forma notable en la expansión del medio construido. Asimismo, esta situación se potenció aún más a partir de la denegación por parte del gobierno provincial al pedido de independencia de las comunas de Santa Mónica y Santa Rosa del Río respecto de la localidad de Santa Rosa de Calamuchita, por lo cual en el año 2006 las tres localidades se anexarían de forma definitiva bajo la categoría de ciudad y con la respectiva ampliación de su ejido municipal.

Posteriormente, desde finales del año 2008 y durante todo el 2009, se identificó otro importante crecimiento del medio construido en la localidad de Santa Rosa de Calamuchita, pero en este caso la mayor parte se debió a la anexión de las comunas de Santa Rosa del Río y Santa Mónica, dando lugar a una mancha urbana más homogénea entre las mismas, la cual alcanzó una superficie aproximada de 1555 ha. Este crecimiento también estuvo favorecido por algunas inversiones municipales e inmobiliarias privadas, a partir del loteo de terrenos baldíos y por las diversas ofertas con fines residenciales.

En cuanto a los principales capitales inversores inmobiliarios, de acuerdo a las consultas realizadas a diferentes inmobiliarias de la localidad, provienen principalmente de Buenos Aires (específicamente del sector sur del Gran Buenos Aires); Santa Fe (de ciudades tales como Rosario, Venado Tuerto y pueblos aledaños al río Paraná); Córdoba Capital y Río Cuarto; y, en menor medida, desde Tierra del Fuego y otras áreas del sur de la Argentina. La mayoría de las inversiones proceden de 
personas físicas y no hay por el momento grandes constructoras que inviertan en infraestructuras inmobiliarias, como grandes cadenas hoteleras o complejos específicos. Asimismo, cabe aclarar que la ciudad se encuentra aún en franco crecimiento, por lo que todavía las inversiones son mínimas respecto a otras ciudades con el mismo perfil turístico.

Finalmente, hacia el año 20r6, la ciudad de Santa Rosa de Calamuchita fue creciendo a un ritmo constante, llegando a cubrir una superficie de 2072 ha de manera homogénea hacia todos los puntos cardinales. Para entonces, casi un $60 \%$ de las residencias eran destinadas a alojamientos turísticos o segundas residencias y un $40 \%$ a residencias permanentes. Las primeras se concentran en el norte y oeste de la ciudad, principalmente en los barrios de Santa Mónica y, en menor medida, en el barrio de Santa Rosa del Río; y las segundas se localizaban en el sector centro-sur de la localidad.

También es importante aclarar que en los últimos años se han incrementado las obras de infraestructura pública por parte del Estado municipal y provincial para mejorar los servicios, el aspecto de la ciudad y fomentar así el turismo. Por ejemplo, se puede identificar la reconstrucción de la costanera del río, los puentes carreteros, la creación de una ciclo-vía alrededor del río y también la remodelación del centro de la ciudad y las calles principales, a través de la creación de peatonales.

Por último, si se analiza el gráfico de línea de la figura 4, en el que se representa la evolución de la urbanización de la localidad en todo el período, es posible observar que el ritmo del avance del medio construido en Santa Rosa de Calamuchita ha sido constante, principalmente a partir del ańo 200I, momento en el que no sólo se anexan las comunas de Santa Mónica y Santa Rosa del Río a la localidad bajo estudio (lo que permitió su designación como ciudad), sino también producto del progresivo loteo para su comercialización con fines residenciales.

Para concluir, respecto a la expansión de la mancha urbana, se puede decir que si bien Santa Rosa de Calamuchita creció en cuanto a su medio construido y en términos de población por el desarrollo de las actividades vinculadas al turismo, también vale remarcar que parte de dicho crecimiento se debió a la inclusión de las comunas cercanas a la localidad, las cuales también fueron creciendo y mejorando su infraestructura para poder consagrarse como una única ciudad turística, la más grande del Valle de Calamuchita (figura 3). 
Fuente: Ribert, sobre la base de digitalización sobre imágenes satelitales Landsat TM5 y Landsat ETM8 (2018).

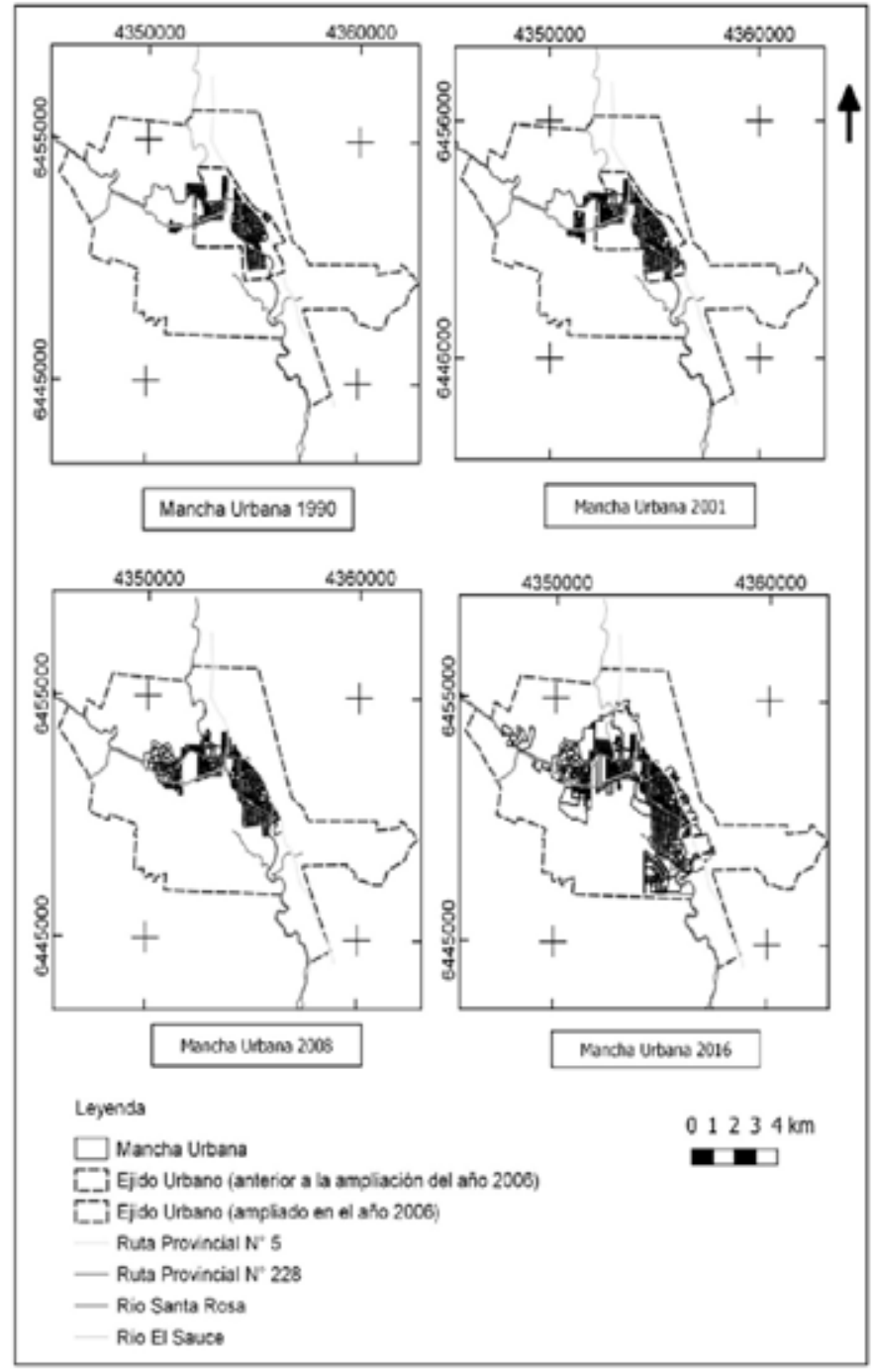

Figura 2. Evolución de la mancha urbana de la localidad de Santa Rosa de Calamuchita (Córdoba) entre 1990 y 2016 


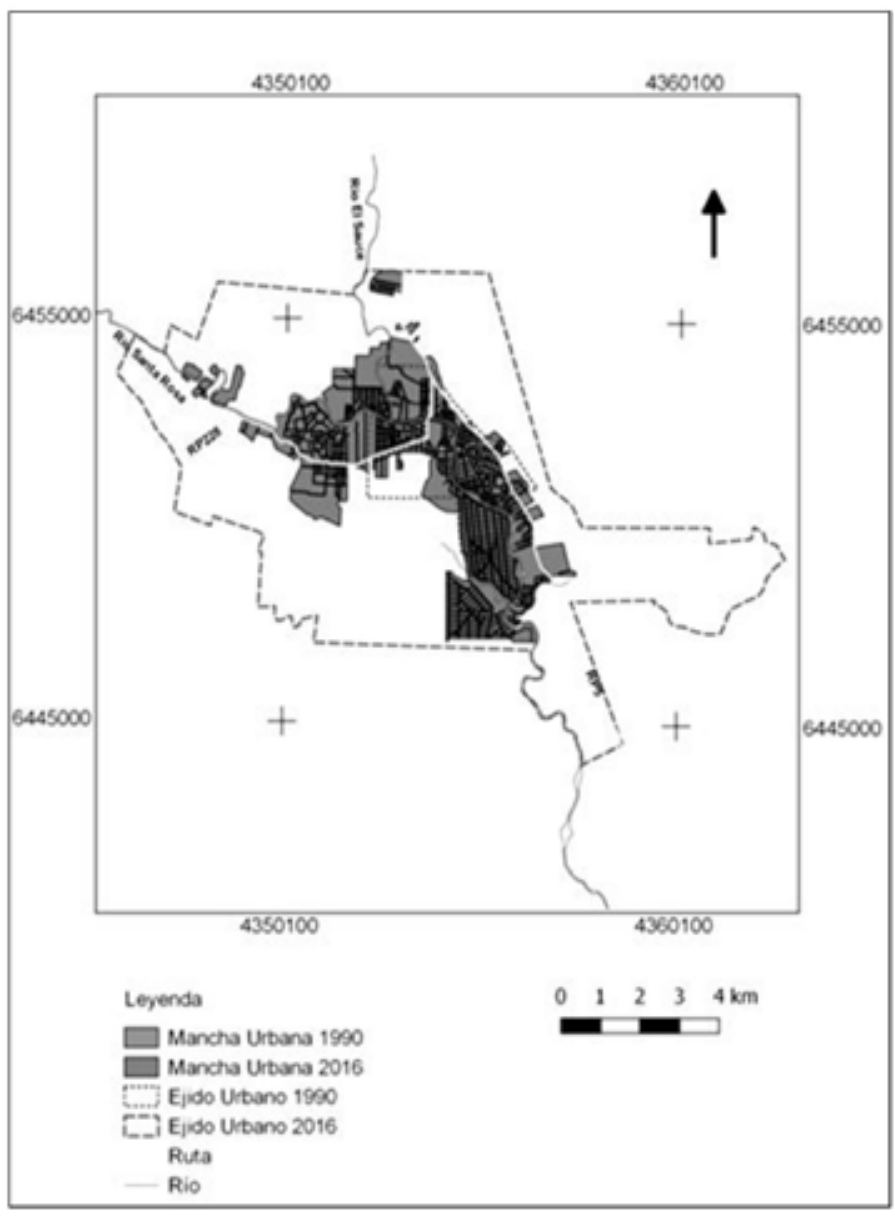

Figura 3. Superposición de la evolución de las manchas urbanas de la localidad de Santa Rosa de Calamuchita (Córdoba) entre los años 1990 y 2016
Fuente: Ribert, sobre la base de digitalización sobre imágenes satelitales Landsat TM5 y Landsat ETM8 (2018). 


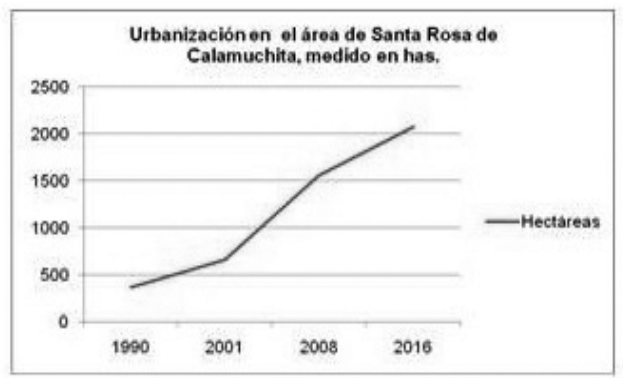

\begin{tabular}{|r|r|}
\hline Año & Hectáreas \\
\hline 1990 & $3^{66}$ \\
\hline 2001 & 661 \\
\hline 2008 & 1555 \\
\hline 2016 & 2072 \\
\hline
\end{tabular}

Fuente: Ribert, sobre la base de los datos recabados en la Figura 4. Urbanización en el área de Santa Rosa de Caladigitalización sobre imágenes satelitales (2018).

\section{Problemáticas ambientales derivadas del crecimiento urbano}

El sostenido crecimiento de Santa Rosa de Calamuchita a lo largo de su río homónimo y en torno a las vías de comunicación, generó en los últimos años un escenario de múltiples problemáticas ambientales. De acuerdo a la información obtenida de algunas entrevistas realizadas a especialistas en la temática ${ }^{9}$, los mismos coincidieron en que el aumento de los desmontes para la construcción edilicia fue la principal problemática ambiental identificada a partir del año 1990. Una situación que se potenció aún más hacia el año 2000 , producto del incesante incremento de las construcciones.

Para estudiar los impactos de este proceso, en el año 2017 se analizaron las especies vegetales presentes en el área de estudio, a través del desarrollo de algunos trabajos de campo en diferentes sectores de la localidad y mediante la construcción de stands, sobre la base de la metodología de Braun Blanquet (1950) y la utilización de la clave dicotómica de Vischi y Oggero (2002) para el reconocimiento de especies nativas y exóticas. En este sentido, se delimitaron cinco stands de $5 \mathrm{~m}^{2}$ cada uno, los cuales se localizaron en aquellas zonas periféricas de la localidad donde se podía reconocer y estudiar la vegetación del lugar.

9 Especialistas en estudios sobre ambiente. 
En el primer stand se registra una gran variedad de especies características del Bosque Chaqueño Serrano y el Espinal. Se observa una estructura de bosque compuesta por dos estratos: el herbáceo y el arbóreo, con predominio de las arbóreas. En el caso del estrato arbóreo, las vegetaciones más representativas eran el Tala (Celtis tala), el Moradillo (Schinus fasciculatus), el Espinillo (Acacia caven), y las epífitas como el Clavel del Aire (Tillandsia hieronymii). La vegetación original de esta zona se caracteriza por ser de una estructura abierta de pastizal y árboles dispersos. En el segundo stand se puede observar un predominio del Chañar (Geoffroea decorticans), el Moradillo (Schinus fasciculatus) y el Tala (Celtis tala), y tal como en el otro stand (I) se caracteriza también por ser una estructura abierta y con arbolada dispersa. Tanto en el primero como en el segundo stand, al estar localizados en las periferias de la zona urbana del área de estudio, no había presencia (o si la hay es en menor cantidad) de especies exóticas. En cambio, el tercer stand sí se caracterizó por tener un predomino principalmente de especies exóticas. Según las especies reconocidas por la clave dicotómica, estas son: Acacia negra (Acacia melanoxylon), pero también se observó Zinnia silvestre (Zinnia peruviana), Aligustre (Ligustrum lucidum) y Cardos (Cynara cardunculus); y en menor medida Paraíso (Melia azedarach), Olmo común, Negrillo (Ulmus minor Mill) Crataegus (Pyracantha angustipholia), y Algarrobo (Ceratonia siliqua Linn). En este caso, se caracteriza por ser una estructura cerrada, con mayor concentración de los árboles, ya que al ser más altos y sus copas más grandes ocupan una mayor superficie, por lo que proyectan mayor sombra. Tanto el cuarto como el quinto stand tenían un predominio de especies exóticas como el Aligustre (Ligustrum lucidum) y la Acacia negra (Acacia melanoxylon), pero también se pudieron observar algunas especies nativas como el Chañar (Geoffroea decorticans), el Moradillo (Schinus fasciculatus), el Tala (Celtis tala) y el Espinillo (Acacia Caven), por lo cual presentan una estructura semi-cerrada con una importante concentración de árboles. La composición de los stand tres, cuatro y cinco presentan mayores especies exóticas dado que se implantaron en zonas urbanizadas. A su vez, se pudo observar que los terrenos desmontados están dominados por especies exóticas en lugar de especies nativas.

En cuanto a la cobertura de suelo con vegetación para el año 1990 (figura 5), tomando como referencia al ejido urbano actual (9247 ha), era de aproximadamente $848 \mathrm{I}$ ha (vale aclarar que dicha cifra corresponde sólo a la vegetación, no contempla a la mancha urbana, 366 ha, 
ni a las superficies cultivadas, 400 ha aproximadamente). Para el año 20I6, la cobertura vegetal alcanzó aproximadamente las 6775 ha, sin tener en cuenta a la mancha urbana (2072 ha) ni al cultivo (400 ha) que se mantenía estable. Por lo tanto, se pudo observar que hubo un retroceso de 1706 ha de cobertura vegetal que evidencia la multiplicación de los desmontes por la expansión del medio construido. Esto derivó en la pérdida de vegetación autóctona, agudizando la competencia ecológica directa con especies exóticas relacionadas con la urbanización (a causa del uso de especies foráneas para la ornamentación). Con relación a esto, se puede afirmar que en el área de estudio la urbanización fue ganando terreno sobre la cobertura vegetal de la zona y que, a su vez, con la introducción de las especies exóticas, se fueron reduciendo cada vez más las especies nativas que se encontraban en el lugar.
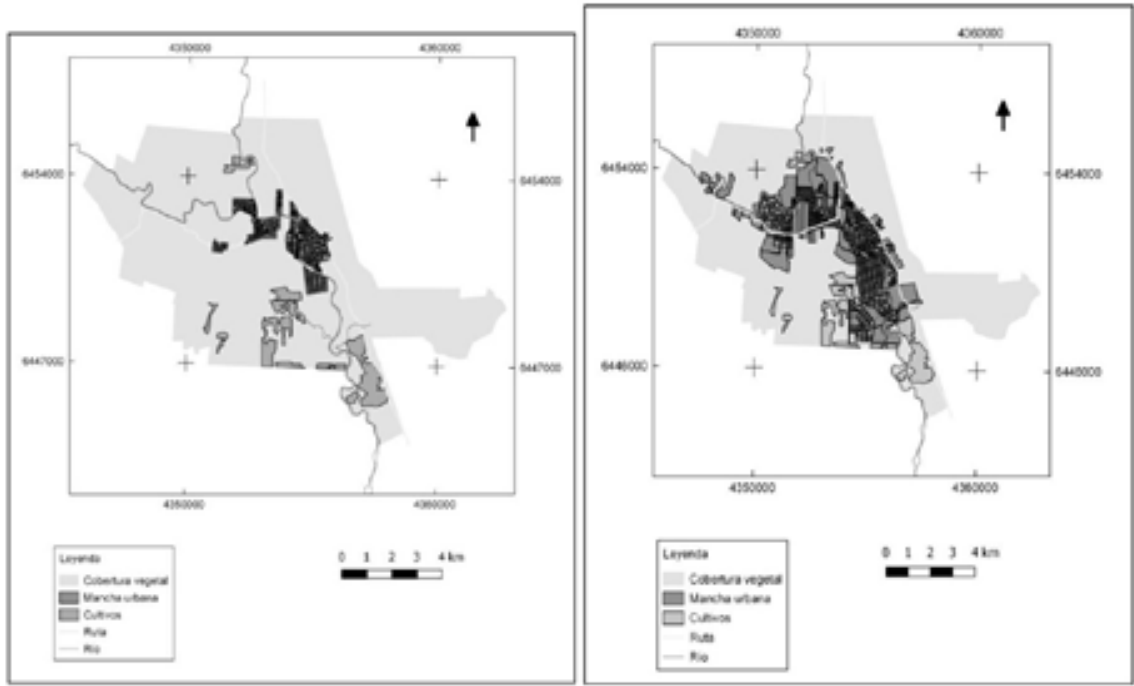

Fuente: Ribert, sobre la base de imágenes satelitales Landsat TM5 y Landsat ETM8 (2018).
Figura 5. Evolución de la cobertura vegetal entre los años 1990 y 2016 en Santa Rosa de Calamuchita

Otro escenario vinculado a las problemáticas ambientales ha sido el avance de las construcciones hacia las Sierras Chicas. Si bien en la actualidad no se registraron importantes problemas, esta situación podría generar a futuro un potencial conflicto ya que las construcciones 
mantienen su avance hacia aquellas zonas con mayor pendiente, lo que podría ocasionar, junto al desmonte, problemas de coladas o crecientes súbitas. Con relación a esto último, se recupera el concepto de "ladera urbana” de Caballero Zeitún (20II ${ }^{\mathrm{ro}}$. Bajo este concepto, la ladera urbana es el producto de las prácticas sociales en cuanto al uso y las formas de ocupación de las superficies terrestres inclinadas, donde se emplazan los asentamientos humanos.

En el caso del área de estudio, la población que se asienta al pie de las Sierras Chicas presenta un alto poder adquisitivo y, como ya se mencionó anteriormente, las construcciones están destinadas al turismo o casas de segundas residencias. Al construir en zonas inestables, se exponen al riesgo de derrumbes, desprendimientos de rocas, avalanchas, entre otros. A su vez, esto modifica la forma de infiltración del suelo producto de las edificaciones emplazadas en sectores de laderas. De este modo, el suelo queda al descubierto (sin cobertura vegetal) o, en ciertos casos, impermeabilizado por la urbanización, lo cual dificulta la infiltración de agua, dando lugar a que la misma escurra, pudiendo generar así desprendimientos de rocas, coladas de barro, incremento y aceleración del escurrimiento superficial del agua, entre otros.

Otra área de conflicto es el sector norte de la ciudad en el que se localiza un basural a cielo abierto. Esta situación genera otra problemática debido a que la localidad también crece hacia esa zona, por lo que se acerca cada vez más a dicho basural, a tal punto de observarse algunos emplazamientos en sectores aledaños al mismo. En la época estival $^{\text {II }}$, dada la cantidad de residuos que produce la ciudad, la problemática se agrava. En los últimos ańos, los residuos sólidos urbanos han constituido una gran problemática, debido a los impactos del incremento de la población, el crecimiento del medio construido y de la actividad económica predominante (el turismo), en términos de la importante afluencia de personas que se acerca a la ciudad en los distintos

10 Quien la define como la forma de ocupación del suelo sobre un accidente geográfico o una cadena de accidentes geográficos con declives de alta o mediana pendiente (entre los $45^{\circ}$ y $30^{\circ}$ ), con un uso intensivo en vivienda, equipamiento urbano e infraestructura económica y social, susceptible de presentar movimientos de subsidencia o colapso por la incidencia y combinación de factores internos y externos, que constituyen un riesgo de desastre para sus ocupantes y sus bienes.

11 Que es cuando la localidad de Santa Rosa acrecienta su población en más del 40\%, producto del arribo de turistas al lugar. 
momentos del año. Asimismo, también se debe mencionar las pocas acciones integrales desarrolladas para el manejo de los residuos, ya que son incinerados a cielo abierto sin ningún tipo de tratamiento, situación que genera problemáticas de contaminación en la salud de la población aledaña, tanto por las toxinas liberadas al aire como por las voladuras de residuos hacia la localidad, principalmente en momentos de viento norte, provocando así graves inconvenientes a los vecinos de los barrios más cercanos al basural. Por último, también se pueden destacar otras problemáticas ambientales vinculadas al basural tales como: la contaminación del suelo y de las aguas superficiales y subterráneas. Todo ello agravado por la incineración descontrolada y la disposición de los residuos sin tratamiento alguno, lo que crea las condiciones ideales para la proliferación de roedores peligrosos para la población, por ser portadores y transmisores de enfermedades.

\section{Reflexiones finales}

De acuerdo a lo trabajado, se ha podido dar cuenta de una notable expansión del medio construido en la localidad de Santa Rosa de Calamuchita a lo largo de todo el período analizado (1990-20I7), producto de los diferentes eventos acontecidos y relacionados a la actividad turística y a la anexión de las comunas aledañas a dicha localidad. Asimismo, esta situación se acompañó de un importante crecimiento poblacional, lo que derivó en la categorización de "ciudad". Del análisis de las imágenes satelitales y la cartografía obtenida, también se puede observar que el crecimiento del medio construido se ha realizado a través de diversas modalidades de loteo, hacia los distintos puntos cardinales del área de estudio, avanzando principalmente sobre zonas con cobertura de suelo vegetal y con distintos grados de pendiente.

Por otro lado, cabe destacar que la actividad turística no sólo es la principal actividad económica de la ciudad, sino que, como consecuencia de su desarrollo, han tenido lugar diferentes modificaciones del espacio construido, reflejadas en distintas problemáticas. Entre ellas se distinguen: el reemplazo de cobertura vegetal, la introducción de especies exóticas, la multiplicación y la falta de tratamiento de los residuos urbanos (como consecuencia de ello la presencia del basural a cielo abierto). 


\section{Referencias bibliografía}

Bertoncello, R. (2002). Turismo y territorio. Otras prácticas, otras miradas, Aportes y transferencias, Año $\mathrm{N}^{\circ}$ 6, vol. 2, pp. 29-50. Mar del Plata: CITUNMDP.

Bertoncello, R. (2006). Turismo, territorio y sociedad. El 'mapa turístico de la Argentina', Geraiges de Lemos, A., Arroyo, M. y Silveira, M. L (Comps.) América Latina: cidade, campo e turismo. San Pablo: CLACSO.

Brandi, C., Grandis, G., Carezzano, H. (2015). Utilización de indicadores ambientales para estudiar los efectos del cambio del uso del suelo, en el área de Alpa Corral (Córdoba), V Congreso Nacional de Geografía de Universidades Públicas "Geografías por venir". UNComa. 23-25 de septiembre. En prensa.

Braun, B. J. (I950). Sociología vegetal, estudio de las comunidades vegetales. Buenos Aires: Acme Agency.

Caballero Zeitún, E. (20II). El concepto de Ladera Urbana, Revista Ciencias Espaciales, Vol. $\mathrm{N}^{\circ} 4, \mathrm{~N}^{\circ}$ I primavera.

Cabral, A. C. y Bais, M. S. (2014a). Evolución diferencial de la actividad turística en las localidades serranas de las pedanías de Achiras y San Bartolomé, en el suroeste de la provincia de Córdoba, X Jornadas de Investigación en Geografía (pp. I-9). Departamento de Geografía, Facultad de Humanidades y Ciencias, Universidad Nacional del Litoral, Santa Fe. (2014b). Actividad turística en el sur de las sierras de córdoba. Trayectorias territoriales de las localidades de las pedanías de San Bartolomé y Achiras, X Jornadas de Investigación del Departamento de Geografia (pp. I-I6). 30 y 3 I de Octubre. Universidad Nacional de Río Cuarto, Córdoba.

Cabrera, M. C. (2003). El turismo social como derecho. El acceso a Mar del Plata, territorio de distinción (Tesis de Maestría). Facultad de Filosofía y Letras, Universidad de Buenos Aires, Buenos Aires.

Donadoni, M., Landriscini, G., Schoroeder, R. y Tello, D. (2012). Recreación y turismo rururbano en ciudades intermedias, Gorenstein, S., Hernández, J., y Landriscini, G. Economía urbana y ciudades intermedias: trayectorias pampeanas y nordpatagónicas. $\mathrm{I}^{\circ}$ edición. Buenos Aires: CICCUS.

Galera Morant, E. (20ro). Santa Rosa desde Antaño, I edición. Córdoba: El autor.

Galera Morant, E. (2013). Santa Rosa desde Antaño y sus Barrios, I edición. Córdoba: ENALGAL

García, E. (2018). Turismo residencial: una aproximación a la dinámica turístico-inmobiliaria en la ciudad de Santa Rosa de Calamuchita, Córdoba 
(Argentina), Revista El Periplo Sustentable, $\mathrm{N}^{\circ} 34$. Universidad autónoma del Estado de México.

García. E. y Perrone, L. (20I7). Turismo, pinares y actores sociales en Alpa Corral. Encuentros y desencuentros en los procesos de transformación territorial. (Tesis final de Licenciatura en Geografía). Departamento de Geografía, Facultad de Ciencias Humanas, Universidad Nacional de Río Cuarto, Córdoba.

García, E., Perrone, L., Maldonado, G. I., Maffini, M., y Sosa, E. del C. (2015). Sierras del sur de Córdoba: turismo, pinares y actores. Encuentros y desencuentros en su proceso de transformación territorial, $V$ Congreso Nacional de Geografía de Universidades Públicas "Geografias por venir". UNComa. 23-25 de septiembre. En prensa.

Gervasoni, C. (2003). Debilidad política y crisis financiera: una explicación del fracaso de De la Rúa, Universidad Católica Argentina (UCA), Universidad Torcuato Di Tella (UTDT), Universidad del CEMA (UCEMA). Publicado en Dallas, Texas.

Maffini, M. (2014). El proceso de valorización turística en el sector central de las sierras de Córdoba: un análisis desde la geografía del turismo, Jornadas de Investigación de la Facultad de Ciencias Humanas 20I5. UNRC. 20 y 2I de agosto. Aceptado para Publicación. En prensa.

- (2015). Actualidad de la práctica turística en un sector de las sierras de Córdoba, V Congreso Nacional de Geografía de Universidades Públicas "Geografías por venir". UNComa. 23-25 de septiembre. En prensa.

Ministerio de Turismo de la Nación (2011). Plan Federal Estratégico de Turismo Sustentable. Actualización 2012-2020. Buenos Aires. Presidencia de la Nación.

Pastoriza, E. (20II). La conquista de las vacaciones. Breve historia del turismo en Argentina. Buenos Aires: Edhasa.

Pertierra Cánepa, F. y Pantanetti, M. (2011). El fideicomiso y el boom inmobiliario argentino, Serie Documentos de Trabajo, No. 45I. Buenos Aires: Universidad del Centro de Estudios Macroeconómicos de Argentina (UCEMA).

Santos, M. y Silveira, M. (2005). O Brasil. Territorio e sociedade no inicio do século XXI. Rio de Janeiro: Ed. Record.

Sosa, E. del C., Maldonado, G. I., Grandis, G., Lucero, F., Brandi, C., y Valenzuela, M. C. (2015). El proceso de construcción espacial de las sierras del sur cordobés y sus problemáticas ambientales emergentes, Jornadas de Investigación de la Facultad de Ciencias Humanas 20I5. UNRC. 20 y 2I de agosto. Aceptado para Publicación. En prensa. 
Sosa, E. del C., Moriconi, L., Cabral, A. C. y Maldonado, G. I. (2013). Definición de macroambientes en base a características socio-económicas en el suroeste de la provincia de Córdoba, Actas del IV Congreso Nacional de Geografia de Universidades Públicas. XI Jornadas Cuyanas de Geografía. 2326 de octubre. Instituto y Departamento de Geografía. FFyL. Universidad Nacional de Cuyo. ISSN. Publicación en Disco Compacto.

Villar, Ma. d. C., y Bilbao, R. F. (200o). Paisajes litorales: imágenes del pasado, sociedad y territorio, Amadis (Brest) $\mathrm{N}^{\circ} 4$.

Vischi, N. y Oggero, A. (2002). Bosque Autóctono el Espinal un área protegida. Universidad Nacional de Río Cuarto, Córdoba.

\section{Fuentes}

Signorile, A. (2018). Secretaría de Turismo, [en línea] Recuperado de: http:// www.starosacalamuchita.com.ar/la-ciudad/historia/ . 